\title{
PENGARUH PENGGUNAAN MEDIA SANDPAPER LETTER TERHADAP KEMAMPUAN MENGENAL HURUF ANAK USIA 4-5 TAHUN DI TAMAN KANAK-KANAK ISLAM BUDI MULIA PADANG
}

\author{
Fita Rahmadani ${ }^{1}$, Dadan Suryana $^{2}$, Sri Hartati ${ }^{3}$ \\ Fakultas Ilmu Pendidikan \\ Universitas Negeri Padang \\ Email: fitaciptadi@gmail.com
}

\begin{abstract}
ABSTRAK
Pengetahuan tentang huruf bagi anak 4-5 tahunsangat penting untuk proses belajar membaca dan menulis, oleh karena itu untuk merealisasikan pembelajaran mengenal huruf di perlukan media yang sesuai dengan karakteristik perkembangan anak. Penelitian ini bertujuan untuk mengetahui seberapa besar pengaruh media sandpaper letter terhadap kemampuan mengenal huruf anak usia 4-5 tahun. Metode penelitian ini menggunakan pendekatan kuantitatif yang berbentuk quasi eksperiment. Hasil penelitian menunjukan bahwa anak pada kelass eksperimen yang menggunakan media sandpaper letter memiliki hasil rata-rata yang tinggi di bandingkan dengan anak pada kelas control yang menggunakan media konvensional. Maka dapat ditarik kesimpulan bahwa penggunaan media sandpaper letter besar pengaruhnya terhadap kemampuan mengenal huruf anak usia 4-5 tahun.
\end{abstract}

Kata kunci: Sandpaper Letter, kemampuan mengenal huruf

\begin{abstract}
Knowledge of letters for children for children 4-5 years old is very important for the process of reading and writing, therefore children should be introduced to letters early. To realize learning to recognize letters, media is needed in accordance with the characteristics of child development. This study aims to determine how much influence the use of sandpaper letter media on the ability to recognize the letters of children aged 4-5 years. This research method uses a quantitative approach in the form of quasi experiments. The results showed that children in the experimental class using sandpaper letter had high average results when compared to the control class using conventional media. it can be concluded that the use of sandpaper letter media has a large influence on the ability to recognize the letters of children aged 4-5 years.
\end{abstract}

Keywords: Sandpaper letter, Ability in alphabet knowlege

\section{PENDAHULUAN}

Pendidikan anak usia dini yang di singkat PAUD merupakan suatu upaya pembinaan melalui pemberian rangsangan pendidikan anak untuk membantu pertumbuhan dan perkembangan jasmani dan rohani yang di tujukan pada anak usia nol sampai enam tahun agar nak memiliki kesiapan dalam memasuki pendidikan yang lebih lanjut. Taman Kanak-kanak adalah salah satu penyelenggara pendidikan 
anak usia dini yang menekankan pada prinsip bermain sambil belajar dan belajar seraya bermain. Berbagai bidang pengembangan dan pertumbuhan di sajikan pada pendidikan taman kanak-kanak, satu dia antaranya adalah pengembangan bahasa. Pengembangan bahasa memungkinkan anak dapat berkomunikasi melalui pengenalan simbol-simbol huruf.

Keterampilan bahasa merupakan kemampuan yang penting untuk berkomunikasi terutama bagi anak yang sudah berada dilingkungan pendidikan pra-sekolah. Pendidikan pra-sekolah merupakan sarana yang sangat penting untuk mengembangkan kemampuan bahasa. Kemampuan bahasa yang perlu di kuasai anak untuk melanjutkan pendidikan selanjutnya adalah kemampuan membaca dan menulis. Memahami pentingnya pembelajaran bahasa bagi anak maka pengenalan huruf adalah pelajaran yang tepat di perkenalkan pada anak usia 4-5 tahun untuk menuanjang kemampuan yang di butuhkan anak dalam melanjutkan pendidikan ke jenjang pendidikan yang lebih tinggi. Mengenalkan huruf pada anak haruslah sesuai dengan tingkat perkembangan anak.

National Association For The Educating Of Young Children (NAEYC) dan International Reading Association (IRA) membuat pernyataan resmi yang menyangkut kemampuan membaca dan menulis anak usia 3-5 tahun. Pernyataan ini menjelaskan bagaimana cara yang baik untuk membangun dasar-dasar kemampuan meulis dan membaca, suatu kompetensi yang harus di miliki anak sebelum membaca dan menulis yaitu anak mampu mengidentifikasi beberapa huruf dan kecocokan antara bunyi huruf dengan simbolnya. National Academi Of Sciences menerbitkan juga sebuah dokumen berdasarkan penelitian yang berjudul "preventing reding diffieculties in young children" oleh Snow pada tahun 1998, yang menyampaikan daftar keterampilan yang harus dimiliki oleh anak 3-5 tahun sebelum memasuki pelajaran membaca adalah mengenal dan menyebutkan semua huruf alfabet meliputi bunyi, kesepadanan bunyi dengan huruf. Serta anak dapat menggunakan kesadaran fonemik dan pengetahuan huruf untuk mengeja secara mandiri yang di ciptakan sendiri dan kreatif (Seefeld. 2008). 
Pentingnya kemampuan mengenal huruf ini sebagai dasar awal anak menguasai kemampuan membaca maka kemampuan mengenal huruf seharusnya dikembangkan sesuai dengan kebutuhan dan karakteristik anak, karena melalui simbol-simbol huruf anak akan mampu berkomunikasi serta dapat meningkatkan pengetahuan dan wawasan anak. Dalam menstimulasi kemampuan mengenal huruf usia 4-5 tahun perlu dilakukan agar jangan sampai anak merasa vdipaksa untuk mengenal semua huruf dengan pembelaran yang kaku. Pada hasil pengematan anak usia 4-5 tahun di Taman Kanak-kanak Islami Budi Mulia Padang belum mampu untuk mengenal macam-macam bunyi dan bentuk huruf hal ini di sebabkan anak kebingungan memahami huruf yang hampir serupa. Selain itu terdapat pula anak yang belum tertarik dengan kegiatan mengenal simbol-simbol huruf. Peranan guru dalam mengembangkan kemampuan berbahasa anak khususnya mengenal huruf adalah menyajikan pembelajaran dan media yang menarik, sesuai dengan perkembangan, pengalaman dan keinginan anak. Upaya yang dapat dilakukan untuk mengembangkan kemampuan mengenal huruf anak salah satunya adalah dengan menggunakan media sandpaper letter.

Sandpaper letter atau huruf raba adalah media yang digunakan untuk mengenalkan huruf kepada anak dengan cara yang kongkret yang terbuat dari kayu persegi dengan ketebalan $1 \mathrm{~cm}$ dengan huruf yang berasal dari kertas ampelas (Pramita,2017:154). Media sandpaper letter atau media kertas ampelas merupakan alat peraga edukatif metode Montessori di area bahasa yang bertekstur sebagai alat bagi anak untuk meraba sebuah simbol huruf. Selain untuk mengenalkan huruf, sandpaper letter adalah salah satu media pembelajaran yang digunakan dalam metode montessori sebagai latihan untuk membagun mekanisme otot yang diperlukan untuk kemampuan memegang dan menngunakan alat tulis kemudian, jari anak yang telah terlatih melalui kegiatan meraba bentuk-bentk huruf menjadi pelengkap penegtahuan visual anak tentang huruf (Gutek, 2015). Dengan kematangan anak dalam mengenal huruf seperti itu anak akan lebih siap untuk latihan selanjutnya yaitu membaca dan menulis. 
Gutek (2015:319-321) mengatakan bahwa montessori dalam mengajarkan huruf alfabet dengan media sandpaper letter memulai dengan mengenalkan huruf vokal baru kemudian huruf konsonan, proses pembelajaran huruf ini menurut pada tiga priode yaitu: 1). penghubungan sensasi visual dan otot-sentuhan dan bunyi huruf. 2). Presepsi, Anak harus tau bagaimana membandingkan dan mengenali bentuk-bentuk huruf ketika anak mendengar bunyinya. 3). Bahasa, Anak harus dapat menjawab pertanyaan guru mengenal huruf yang di tunjuk oleh guru pada saat pembelajaran huruf berlangsung.

\section{METODE PENELITIAN}

Berdasarkan masalah yang di teliti yaitu melihat bagaimana "pengaruh penggunaan media sandpaper letter terhadap kemampuan mengenal huruf anak usia 4-5 tahun di taman kanak-kanak islam budi mulia padang" maka bentuk penelitian yang di gunakan adalah pendekatan kuantitatif dengan masalah dan tujuan yang telah di kemukaan , jenis penelitian ini adalah eksperiment. Menurut Sugiono (2016:107) metode penelitian eksperimen merupakan metode penelitian yang digunakan untuk melihat pengaruh perlakuan tertentu terhadap suatu kondisi yang dapat dikendalikan. Kemudian penelitian ini menggunakan desain quasi eksperiment.

Desain quasi eksperiment menggunakan kelas kontrol tetapi tidak dapat berfungsi sepenuhnya untuk mengontrol variable-variabel luar yang dapat mempengaruhi pelaksanaan penelitian eksperimen (Sugiono, 2016:114). Dalam penelitian ini peneliti berusaha melihat bagaimana pengaruh penggunaan media sandpaper letter terhadap kemampuan mengenal huruf anak usia 4-5 tahun di Taman Kanak-kanak Budi Mulia Padang dengan membandingkan hasil belajar kelas eksperimen dan kelas kontrol. Mula-mula kedua kelas di berikan pre-test. Kemudian kelas eksperimen diberi perlakuan (treatment) dengan menggunakan media sandpaper letter dan kelas kontrol dengan cara yang biasa di lakuakan guru yaitu menggunakan media konvensional berupa kartu huruf. Selanjutnya kedua kelompok 
kelas sampel diberikan post-test untuk melihat hasil akhir nilai yang akan di bandingkan.

Teknik pengambilan sampel pada penelitian ini menggunakan porpose sampling kerena dalam menentukan sampel penelitian ini didasarkan pada tujuan tertentuseperti yang di katakana Sukardi (2012:74) bahwa porpose sampling adalah teknik penggambilan sampel yang di dasari atas tujuan. Tujuan peneliti menggunakan teknik pengambilan sampel ini adalah untuk mendapaktan hasil yang signifikan dari penggunaan media sandpaper letter terhadap kemampuan mengenal huruf anak usia 4-5 tahun di taman kanak-kanak islam budi mulia padang. Berdasarkan uraian di atas maka di ambil sampel sebanyak dua kelasyakni kelompok A1 dan A2 dimana kelompok A1 menjadi kelas eksperimen dan A2 sebagai kelas control dengan perbandingan jumlah anak yang sama yaitu 10 orang. Sebelumnya untuk menengetahui hasil penelitian ini instrument penelitian telah di uji dengan hasil reabilitas tes 0.84 dengan prediakt sanggat tinggi, yang artinya reabilitas menunjuk pada satu pengertian bahwa suatu instrument cukup dapat di percaya untuk di gunakan sebagai alat pengumpulan data karena instrument sudah baik.

\section{HASIL DAN PEMBAHASAN}

\section{Hasil}

Hasil penelitian yang di lakukan di taman kanak-kanak budi mulia padang dengan jumlah 100 anak, peneliti mengambil 20 anak yang di jadikan sampel penelitian. sampel penelitian terbagi dalam dua kelompok terdiri dari 10 anak di kelas A1 yang di jadikan kelas eksperimen, dan 10 anak di A2 yang di jadikan sebagai kelas kontrol. Hasil pre-test pada 10 anak di kelas eksperimen menunjukan bahwa nilai tertinggi anak adalah 68,75 dannilai terendah adalah 50. Dengan nilai rata-rata anak 58,12, jumlah nilai keseluruhan 58,12 median 63,5 standar deviasi 6,87 dan median adalah 62,83 . Sedangkan di kelas kontrol pada jumlah anak yang sama nilai tertingginya adalah 68,75 dan nilai terendahnya 50. Kelas control memiliki jumlah keseluruhan 
568,7 sehingga rata-rata anak 56,87 standar deviasi 5,18 dan mediannya adalah 59,5. Sebagaimana dijelaskan pula pada grafik di bawah ini:

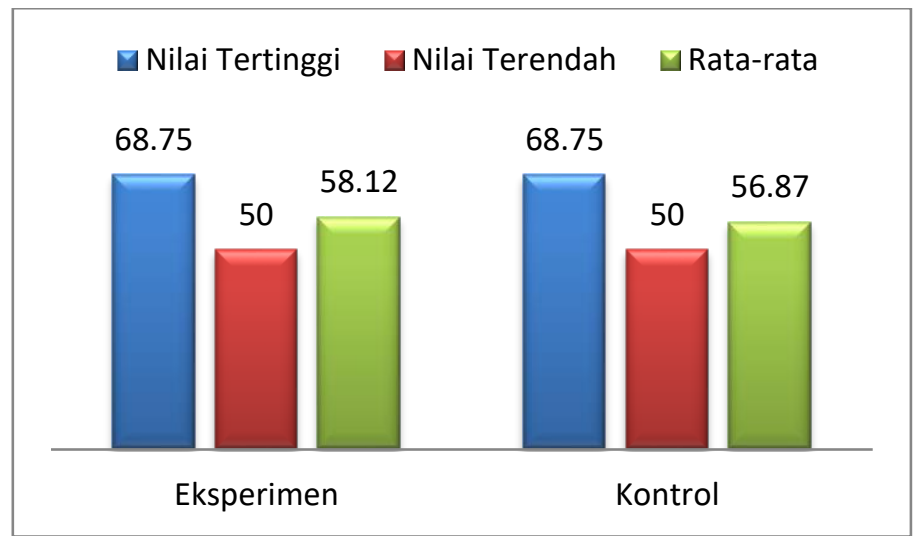

Sedangkan hasil post-test kelas eksperimen dengan jumlah anak 10 orang nilai rata-rata anak adalah 78,12 dengan nilai tertinggi 93,75 dan nilai terendah 68,75 dan jumlah keseluruhan nilai anak adalah 781,25 dengan median 81,75 standar deviasi delas eksperimen 8,14 dan nilai variansnya 66,25. Pada kelas control dengan jumlah anak yang sama yaitu 10 memiliki jumlah nilai sebesar 712,5 dengan nilai tertinggi hanya 81,25 dan nilai terendah 56 , median 71,75 standar deviasinya 7,17 dan nilai variansnya 51,40. Berikut ini adalah table yang menjelaskan hasil post-test :

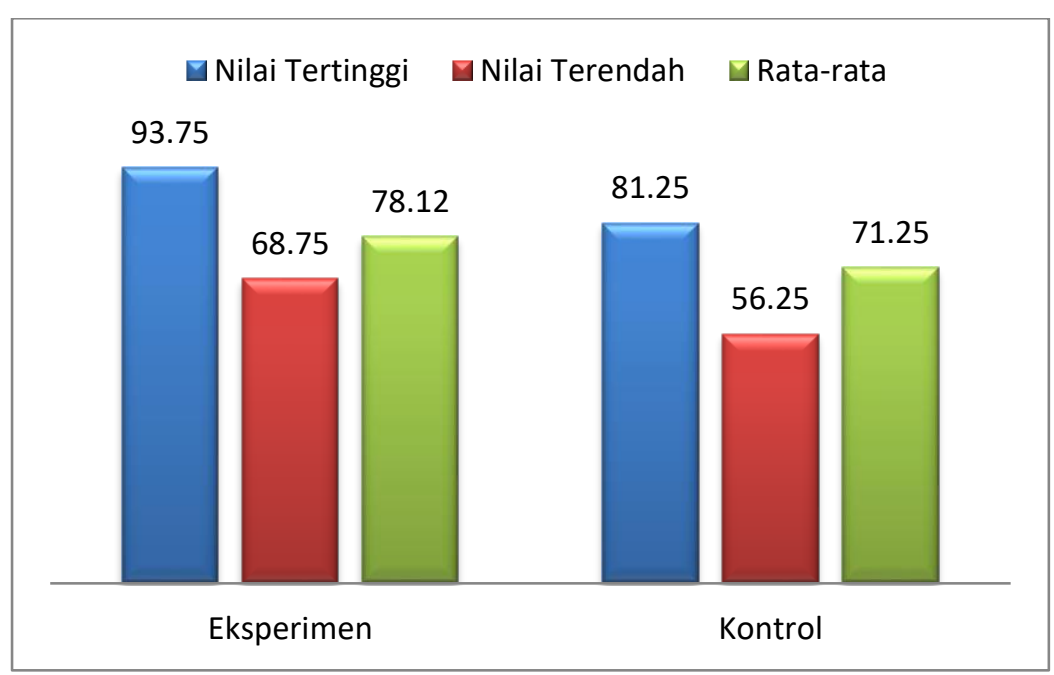


Selanjutnya sekapitulasi hasil Pre-test Post-test kemampuan mengenal suruf anak di kelompok eksperimen dan kelompok kontrol disajikan agar dapat membandingkan perubahan setelah tahap penelitian diselesaikan.

\begin{tabular}{|c|c|c|c|c|}
\hline \multirow{2}{*}{ Variabel } & \multicolumn{2}{|c|}{ Pre-Test } & \multicolumn{2}{c|}{ Post- Test } \\
\cline { 2 - 5 } & $\begin{array}{c}\text { Eksperimen } \\
\text { (A1) }\end{array}$ & $\begin{array}{c}\text { Kontrol } \\
\text { (A2) }\end{array}$ & $\begin{array}{c}\text { Eksperimen } \\
\text { (A1) }\end{array}$ & $\begin{array}{c}\text { Kontrol } \\
\text { (A2) }\end{array}$ \\
\hline N & 10 & 10 & 10 & 10 \\
\hline Nilai tertinggi & 68,75 & 68,75 & 93,75 & 81,25 \\
\hline Nilai terendah & 50 & 50 & 68,75 & 56,25 \\
\hline Jumlah nilai & 581,2 & 568,7 & 781,25 & 712,5 \\
\hline Median & 62,83 & 59,5 & 81,75 & 71,75 \\
\hline Rata-rata & 58,12 & 56,87 & 78,12 & 71,25 \\
\hline SD & 6,87 & 5,18 & 8,14 & 7.17 \\
\hline SD & 47,2 & 26,8 & 66,25 & 51,40 \\
\hline
\end{tabular}

Berdasarkan table diatas, dijelaskan bahwa hasil Pre-test kelompok eksperimen dengan jumlah anak 10 orang memperoleh nilai tertinggi 68,75 dan nilai terendah 50. Dari nilai anak kelas eksperimen ini diperoleh jumlah nilai secara keseluruhan 58,12, median 62,83 dengan rata-rata nilainya sebesar 58,12 standar deviasinya 6,87 dan nilai variansnya sebanyak 47,2 sedangkan kelas control dengan jumlah anak 10 orang memperoleh nilai tertinggi 68,75 dengan nilai terendah 50 . Dari nilai kelas kontrol diperoleh jumlah secara keseluruhannya yaitu 568,7 median 59,5 dengan rata-rata nilainya sebesar 56,87 standar deviasinya 26,8.

Sedangkan hasil Post-test pada kelas eksperimen menunjukan dari jumlah anak 10 orang, nilai tertingginya 93,75 dan nilai terendah 68,75. Dari nilai anak kelas eksperimen ini diperoleh jumlah nilai secara keseluruhan yaitu 781,25, median 81,75 dengan rata-rata nilainya sebesar 78,12, standar deviasinya 8,14 dan nilai variansnya 66,25 .

Kemudian pada kelas kontrol dengan jumlah anak 10 orang memperoleh nilai tertinggiv 81,25 dan nilai terendah 56,25 dari nilai kelas kontrol ini di peroleh jumlah 
secara keseluruhan yaitu 712,5, median 71,75 dengan rata-rata nilainya sebesar 71,25 standar deviasinya 7,17 dan nilai variansnya 51,40.

Sete;ah dilakukan analisis data pre test ditemukan bahwa thitung adalah sebesar 0,461 dibandingkan dengan $\alpha$ 0,05 ( $\left.\mathrm{t}_{\text {tabel }}=2.10092\right)$ dengan derajat kebebasan $\mathrm{dk}\left(\mathrm{N}_{1^{-}}\right.$ 1) $+\left(\mathrm{N}_{2}-1\right)=18$ maka dengan demikian $\mathrm{t}_{\text {hitung }}<\mathrm{t}$ tabel yaitu $0,461<2.10092$ dapat diartikan bahwa hasil perhitungan pre-test $\mathrm{H}_{\mathrm{a}}$ ditolak dan $\mathrm{H}_{0}$ diterima oleh karenanya dapat ditarik kesimpulan bahwa tidak ada perbedaan yang signifikan pada pre-test kemampuan anak mengenal huruf antara kelas eksperimen dan kelas control. Ini berarti kemampuan mengenal huruf anak pada tes kemampuan awal belum terlihat.

Kemudian analisis hasil post-test kemampuan mengenal huruf anak setelah diberikan treatmen dengan menggunakan media sandpaper letter dikelas eksperimen dan dikelas control dilakukan seperti biasanya dengan menggunakan media kartu huruf diperoleh rata-rata kelompok eksperimen adalah 78,12 dan dikelas control 71,87. thitung sebesar 2.14018 dibandingkan dengan $\alpha 0,05\left(\mathrm{t}_{\text {tabel }}=2.10092\right)$ dengan derajat kebebasan $\mathrm{dk} \quad\left(\mathrm{N}_{1}-1\right)+\left(\mathrm{N}_{2}-1\right)=18$ dengan demikian thitung $<\mathrm{t}_{\text {tabel }}$ yaitu $2.14018<2.10092$ dapat dikatakan bahwa $\mathrm{H}_{\mathrm{a}}$ diterima dan $\mathrm{H}_{0}$ ditolak.

Ternyata setelah anak diberikan treatmen atau stimulasi dengan menggunakan media sandpaper letter terlihat perubahan yang signifikan terhadap kemampuan mengenal huruf anak. Pemberian stimulasi bertujuan untuk memberikan nilai edukatif dan sebagai bekal bagi pengetahuan bagi anak (Hartati. 2018:2), maka media sandpaper letter dinyatakan besar pengaruhnya terhadap kemampuan mengenal huruf anak.

\section{Pembahasan}

Ternyata setelah anak di berikan treatmen atau stimulasi dengan menggunakan media sandpaper letter terlihat perubahan yang signifikan terhadap kemampuan mengenal huruf anak. Pemberian rangsangan dengan media yang tepat tentu berpengaruh baik pada aspek perkembangan atau pada keterampilan yang hendak dikembangkan pada anak. stimulasi atau rangsangan di berikan dengan tujuan untuk memberikan nilai edukatif dan sebagai bekal bagi pengetahuan bagi anak 
(Hartati.2018;2) Dengan penggunaan media sandpaper letter dapat membuat anak menjadi antusias, aktif, dan menjadikan proses pembelajaran lebih menarik dan menyenangkan bagi anak sehingga anak lepas dari suasana tertekan, dan tidak terbebani. Pada saat penelitian pre-test di kelas eksperimen dan pre-test di kelas kontrol tidak tampak perbedaan yang signifikan diantara kedua kelas, namun setelah dilakukan treatment pada kelas eksperimen dengan anak dibimbing dalam kemampuan mengenal huruf yaitu dengan media Sandpaper letter.

Pada saat peneliti menggunakan media sandpaper letter dalam mengembangkan kemampuan mengenal huruf anak pada kelompok eksperimen (kelas A1) di Taman Kanak-kanak Islam Budi Mulia Padang, semua anak terlihat antusias dan semangat untuk melakukan kegiatan mengenal huruf karena media tersebut begitu menarik bagi mereka. Menggunakan media sandpaper letter lebih memudahkan anak untuk mengembangkan kemampuan mengenal hurufnya sendiri, karena anak dapat menggunakan media sandpaper letter dengan banyak cara yang anak sukai sehingga pembelajaran tersebut bermakna bagi anak dan juga tatanan proses mengenal huruf yang dimulai dari meraba sembari menyebutkan bunyi huruf, kemudian menyalin hasil rabaan huruf yang akan membuat anak merasa berhasil dan mengulangi pada huruf yang lainnya.

Media Sandpaper letter sangat cocok digunakan karena Media Sandpaper letter memberikan pengalaman belajar huruf secara kongkret bagi anak. Sandpaper letter digunakan dengan banyak cara yang berbeda dari media pembelajaran biasanya, media ini sangat cocok bagi anak usiav 4-5 tahun yang belum akrab dengan kegiatan belajar. Media Sandpaper letter mengembangkan kemampuan mengenal huruf anak dengan menyenangkan dan sesuai dengan tahapan kematangan usia anak untuk belajar huruf yakni dengan menyajikan pembelajaaran dan media yang kongkrit bagi anak. 


\section{KESIMPULAN DAN SARAN}

\section{Kesimpulan}

Berdasarkan hasil analisis data yang telah dilakukan maka dapat disimpulkan bahwa hasil penelitian yang dilakukan di Taman Kanak-kanak Islam Budi Mulia Padang dengan rata-rata hasil kemampuan mengenal huruf anak kelas eksperimen (A1) yang dilakukan dengan media sandpaper letter lebih tinggi dibandingkan anak di kelas kontrol (A2) yang dilakukan dengan media kartu huruf yaitu 78,25 kelas eksperimen dan dikelas control adalah 71,25. Dengan demikian media sandpaper letter terbukti besar pengarunya terhadap kemampuan mengenal huruf anak di Taman Kanak-kanak Islam Budi Mulia Padang. Dimana pada kelas eksperimen anak dapat mencapai nilai tertingginya yaitu 93,75 dan sedangkan di kelas control nilai tertinggi anak hanya mencapai 81,25.

Hasil uji hipotesis di dapatkan $t_{\text {hitung }}>t_{\text {tabel }}$ dimana $(\mathbf{2 , 1 4 0 1 8}>\mathbf{2 , 1 0 0 9 2})$, yang dibuktikan dengan taraf signifikan $\alpha 0,05$ ini berarti terdapat perbedaan yang signifikan antara hasil kemampuan mengenal huruf anak yang menggunakan media sandpaper letter dengan kemampuan mengenal huruf anak yang menggunakan media kartu huruf. Dengan demikian penggunaan media sandpaper letter besar pengaruhnya terhadap kemampuan mengenal huruf anak di Taman Kanak-Kanak Islam Budi Mulia Padang.

\section{Saran:}

Dalam rangka memfasilitasi pembelajaran yang inovatif ada baiknya lembaga pendidikan anak usia dini beralih pada media pembelajaran yang dapat menstimulasi kemampuan mengenal huruf anak dengan hasil yang lebih signifikan seperti media sandpaper letter. Kemudian dari hasil penelitian yang telah di paparkan di atas semoga dapat di jadikan literatur bagi peneliti selanjutnya. 


\section{DAFTAR RUJUKAN}

Depdikbud,2014. Peraturan Mentri Pendidikan Dan Kebudayaan Republik Indonesia Nomor 137 Tahun 2014 Tentang Standar Nasional Pendidikan Anak Usia Dini. Jakarta:Depdikbud

Gutek, Gerald Lee (terjemahan), 2015. Metode Montessori. Yogyakarta: Pustaka Pelajar.

Hartati, Sri, Zulminiati, 2018. Pelatihan Pengembangan Media Pembelajaran Stimulasi Sensori Visual Bagi Guru AUD di Kecamatan Batang Anai. Jurnal: Early Childhood Education vol 2 no 2b

Paramita, Vidya Dwina,2017. Jatuh Cinta Pada Montessori: Seni Mengasuh Anak Usia Dini. Yogyakarta:B First (PT bentang Pustaka)

Seefeld, Carol \& Barbara A. Wasik, 2008. Pendidikan Anak Usia Dini: Menyiapkan Anak Usia Tiga, Empat, Dan Lima Tahun Masuk Sekolah. Jakarta: Indeks

Sukardi, 2012. Metodologi penelitian Pendidikan (Kompetensi dan Praktiknya). Jakarta: Bumi Aksara

Sugiono, 2016. Metode Penelitian: Kuantitatif, kualitatif, dan R\&D. Bandung:Alfabeta 